\title{
Níveis de Proteína Bruta para Leitoas dos 30 aos 60 kg Mantidas em Ambiente de Conforto Térmico $\left(21^{\circ} \mathrm{C}\right)^{1}$
}

\author{
Uislei Antonio Dias Orlando ${ }^{2}$, Rita Flávia Miranda de Oliveira ${ }^{3}$, Juarez Lopes Donzele ${ }^{3}$, \\ Aloízio Soares Ferreira ${ }^{3}$, Wilkson de Oliveira Resende ${ }^{4}$, Letícia Silva de Freitas ${ }^{4}$
}

RESUMO - O experimento foi conduzido para avaliar níveis de proteína bruta (PB) para leitoas em crescimento, mantidas em conforto térmico. A temperatura interna da sala manteve-se durante o período experimental em $21,3 \pm 0,53^{\circ} \mathrm{C}$, a umidade relativa em $70,5 \pm 5,11 \%$ e o Índice de Temperatura de Globo e Umidade (ITGU) calculado no período em 68,7 $\pm 0,93$. Foram utilizadas 40 leitoas mestiças, com peso inicial médio de 29,4 $\pm 1,42 \mathrm{~kg}$, em delineamento de blocos ao acaso com cinco tratamentos (16, 17, 18, 19 e 20\% de PB), quatro repetições e dois animais por unidade experimental. As rações experimentais foram isoenergéticas, com $3400 \mathrm{kcal}$ de ED/kg de ração, e formuladas para satisfazerem às exigências dos animais, exceto em PB. A ração e a água foram fornecidas à vontade até o final do experimento, quando os animais atingiram peso médio de 60,6 $\pm 1,76 \mathrm{~kg}$. O nível de PB da ração influenciou o ganho de peso diário (GPD), que aumentou, e a conversão alimentar (CA), que melhorou linearmente. Apesar do efeito linear dos níveis de PB sobre o GPD e CA, o modelo "Linear Response Platô" (LRP) foi o que melhor se ajustou aos dados, estimando em 18,78 e 19,15\%, os níveis de PB a partir do qual o GPD e a CA, permaneceram em um platô. Os consumos diários de proteína e lisina aumentaram linearmente em razão do nível de PB da ração, porém não se observou efeito dos tratamentos sobre os consumos de ração e de energia digestível diários. Concluiu-se que leitoas em crescimento, mantidas em ambiente de conforto térmico, exigem 19,15\% de PB na ração, correspondendo a um consumo de 343 e 19,08 g/dia de proteína e lisina total, respectivamente.

Palavras-chave: exigência, fase crescimento, suínos fêmeas, termoneutralidade

\section{Crude Protein Levels for Gilts from 30 to $60 \mathrm{~kg}$ Kept Under Thermoneutral Environment $\left(21^{\circ} \mathrm{C}\right)$}

\begin{abstract}
This experiment was conducted to evaluate levels of crude protein (CP) for gilts in growing phase, maintained under thermal comfort. The internal temperature at room was kept during the experimental period in $21.3 \pm 0.53^{\circ} \mathrm{C}$ with relative humidity of $70.5 \pm 5.11 \%$. The calculated black globe humidity index (BGHI) in this period was $68.7 \pm 0.93$. Forty crossbred gilts with average initial weight of $29.4 \pm 1.42 \mathrm{~kg}$ were used in an experimental design of randomized blocks with five treatments $(16,17,18,19$ e $20 \%$ de CP), four replicates and two animals per experimental unit. The experimental isoenergetics rations with $3,400 \mathrm{kcal}$ of DE/kg, were formulated to meet the requirements of animals, except to CP. The rations and water were feeding ad libitum to animals, until the final of experimental period when gilts reached the average weight of $60.6 \pm 1.76 \mathrm{~kg}$. The CP level of ration influenced the average daily weight gain $(\mathrm{ADWG})$ that increases and the feed:gain $(\mathrm{F}: \mathrm{G})$ ratio that improved linearly. In spite of linear effect of CP levels on ADWG and F:G ratio the model of "Linear Response Plateau" (LRP) was one that better adjusted to the data estimating respectively in 18.78 and $19.15 \%$ the levels of CP occurred a plateau. The daily intakes of protein and lysine increase linearly with crescent level of CP on ration. However it did not observe effect of $\mathrm{CP}$ levels on daily intakes of ration and digestible energy. It was concluded that gilts from 30 to $60 \mathrm{~kg}$ kept under thermoneutral environment require $19.15 \%$ of CP on ration associated with the intakes of $343 \mathrm{e} 19.08 \mathrm{~g} / \mathrm{day}$ of crude protein and lysine, respectively for better performance.
\end{abstract}

Key Words: female swine, growing phase, requirements, thermoneutral environment

\section{Introdução}

A exigência de proteína de suínos é influenciada por diversos fatores, entre os quais se incluem genética, sexo, concentrações de energia e proteína da ração e o ambiente. Entre os estressores ambientais, a temperatura do ar altera o consumo de alimentos
(EDMONDS et al., 1998) e a fisiologia do animal (OLIVEIRA, 1996) modificando seu potencial de crescimento e a exigência de aminoácidos.

Segundo MÖHN e LANG (1998), quando animais são mantidos em termoneutralidade e com o suprimento adequado de aminoácidos, a deposição de proteína e, conseqüentemente, o ganho de peso,

\footnotetext{
${ }^{1}$ Parte da tese de Mestrado do primeiro autor. Projeto financiado pela FAPEMIG.

2 Estudante de Doutorado do DZO/UFV. E.mail: uislei@lycos.com

3 Professor do DZO/UFV. E.mail: flavia@mail.ufv.br; donzele@mail.ufv.br; alosofe@mail.ufv.br

${ }^{4}$ Estudante de Zootecnia do DZO/UFV. Bolsista de Iniciação Científica.
} 
aumentam em razão do consumo de energia, até o limite máximo, geneticamente determinado.

Dessa forma, fica evidente que, para definir a exigência de nutrientes de suínos, há necessidade de avaliar as respostas nutricionais que são determinadas pelas interações entre fatores genéticos e ambientais.

Considerando que a alimentação representa grande parte do custo total de produção (FERREIRA et al., 1996) e a proteína representa, de modo geral, o nutriente de maior custo das rações formuladas para suínos no Brasil, a determinação da exigência deste nutriente em razão das condições ambientais pode representar um impacto positivo sobre o custo.

Suínos alimentados com rações contendo altos níveis de aminoácidos (NOBLET et al., 1987) podem aumentar a perda de calor associada com a mantença, refletindo em aumento no gasto de energia (REEDS et al., 1982).

Desta forma, faz-se necessário o estudo das exigências de acordo com o ambiente em que os suínos são criados. Assim, este trabalho foi realizado para avaliar diferentes níveis de proteína bruta para leitoas, dos 30 aos $60 \mathrm{~kg}$, mantidas em ambiente de conforto térmico $\left(21^{\circ} \mathrm{C}\right)$.

\section{Material e Métodos}

O experimento foi conduzido no Setor de Suinocultura do Departamento de Zootecnia do Centro de Ciências Agrárias da Universidade Federal de Viçosa, em Viçosa, MG.

Foram utilizadas 40 leitoas mestiças (Landrace $\mathrm{x}$ Large White), com idade média de $84 \pm 9$ dias e peso inicial médio de 29,4 $\pm 1,42 \mathrm{~kg}$, em delineamento experimental de blocos ao acaso com cinco tratamentos (16, $17,18,19$ e $20 \%$ de proteína bruta na ração), quatro repetições e dois animais por unidade experimental. $\mathrm{Na}$ formação dos blocos, levaram-se em consideração o peso inicial e o grau de parentesco dos animais.

Os animais, em grupos de dois, foram alojados em gaiolas metálicas, suspensas, com pisos e laterais telados, providas de comedouro semi-automático e bebedouro tipo chupeta, e mantidos em sala de alvenaria com janelas de vidro do tipo basculante, cobertura com telha de barro e forro de madeira.

A temperatura interna da sala foi mantida utilizando-se um conjunto de seis campânulas elétricas, distribuídas em dois corredores, a aproximadamente $40 \mathrm{~cm}$ acima do piso, ligadas a um termostato regulado para temperatura de $20,5^{\circ} \mathrm{C}$, e por dois aparelhos de ar condicionado de 18.000 BTU cada, ligados a um termostato regulado para a temperatura de $22,0^{\circ} \mathrm{C}$.

A temperatura e a umidade relativa internas da sala foram monitoradas diariamente, três vezes ao dia $(8,13$ e $18 \mathrm{~h}$ ), por meio de termômetro de máxima e mínima, termômetro de bulbo seco e bulbo úmido e termômetro de globo negro mantidos em uma gaiola vazia no centro da sala à meia altura do corpo dos animais.

Os valores registrados foram, posteriormente, convertidos no (ITGU) índice de temperatura de globo e umidade, segundo BUFFINGTON et al. (1981) caracterizando o ambiente térmico em que os animais foram mantidos, utilizando-se a seguinte equação:

$$
\text { ITGU }=\text { Tgn }+0,36 \text { Tpo }-330,08
$$

em que $\operatorname{Tgn}=$ temperatura de globo negro, ${ }^{\circ} \mathrm{K}$; Tpo $=$ temperatura do ponto de orvalho, ${ }^{\circ} \mathrm{K}$.

As rações experimentais isoenergéticas (Tabela 1), preparadas à base de milho e farelo de soja, foram formuladas para satisfazerem as exigências dos animais em energia, minerais e vitaminas de acordo com ROSTAGNO et al. (1992). Os diferentes níveis de proteína das rações foram obtidos a partir da diluição dos componentes com constituintes de caráter protéico (milho, farelo de soja, L-treonina e DL-metionina) da ração com $20 \%$ de $\mathrm{PB}$, com uma mistura de amido e areia lavada com similar nível de energia digestível da mistura daqueles componentes. Dessa forma, além das rações permanecerem isoenergéticas, a qualidade da proteína, provavelmente não alterou, uma vez que todos os aminoácidos variaram de acordo com a proteína, assegurando a mesma proporcionalidade entre os aminoácidos nos diferentes níveis protéicos. Para a determinação dos aminoácidos digestíveis dos alimentos utilizados na formulação das rações, foram aplicados os respectivos coeficientes de digestibilidade, propostos pelas tabelas da RHODIMET... (1993).

As rações e a água foram fornecidas à vontade aos animais. Os resíduos de ração do chão foram coletados diariamente e somados às sobras do comedouro no final do período experimental. Os animais permaneceram no experimento até atingirem peso médio de $60,6 \pm 1,76 \mathrm{~kg}$.

Ao término do período experimental, que durou, em média, 35 dias, os animais foram colocados em jejum alimentar por 24 horas. Após o jejum, um animal de cada unidade experimental, com o peso mais próximo de $60 \mathrm{~kg}$, foi abatido, por desensibilização e sangramento. Em seguida, procedeu-se à toalete e à abertura da carcaça para retirada dos órgãos.

As análises estatísticas das variáveis de desempenho (ganho de peso, consumo de ração, de prote- 
Tabela 1 - Composição centesimal das rações experimentais

Table 1 - Centesimal composition of experimental rations

\begin{tabular}{|c|c|c|c|c|c|}
\hline \multirow[t]{2}{*}{$\begin{array}{l}\text { Ingredientes (\%) } \\
\text { Ingredients }\end{array}$} & \multicolumn{5}{|c|}{$\begin{array}{c}\text { Níveis de proteína bruta }(\%) \\
\text { Crude protein levels }\end{array}$} \\
\hline & 16 & 17 & 18 & 19 & 20 \\
\hline $\begin{array}{l}\text { Milho }(7,69 \% \text { PB })^{1} \\
\text { Corn }(7.69 \% C P)\end{array}$ & 50,359 & 53,507 & 56,654 & 59,802 & 62,949 \\
\hline $\begin{array}{l}\text { Farelo de soja }(45,5 \% \mathrm{~PB})^{1} \\
\text { Sovbean meal }(45.5 \% C P)\end{array}$ & 26,654 & 28,319 & 29,985 & 31,651 & 33,317 \\
\hline $\begin{array}{l}\text { L-Treonina } \\
\text { L-Threonine }\end{array}$ & 0,006 & 0,006 & 0,006 & 0,007 & 0,007 \\
\hline $\begin{array}{l}\text { DL-Metionina } \\
\text { DL-Methionine }\end{array}$ & 0,017 & 0,018 & 0,019 & 0,020 & 0,021 \\
\hline $\begin{array}{l}\text { Amido } \\
\text { Starch }\end{array}$ & 18,380 & 13,900 & 9,420 & 4,930 & 0,450 \\
\hline $\begin{array}{l}\text { Fosfato bicálcico } \\
\text { Dicalcium phosphate }\end{array}$ & 1,096 & 1,012 & 0,929 & 0,845 & 0,761 \\
\hline $\begin{array}{l}\text { Calcário } \\
\text { Limestone }\end{array}$ & 0,628 & 0,662 & 0,696 & 0,730 & 0,763 \\
\hline $\begin{array}{l}\text { Mistura mineral } \\
\text { Mineral premix }\end{array}$ & 0,100 & 0,100 & 0,100 & 0,100 & 0,100 \\
\hline $\begin{array}{l}\text { Mistura vitamínica }{ }^{3} \\
\text { Vitamin premix }\end{array}$ & 0,300 & 0,300 & 0,300 & 0,300 & 0,300 \\
\hline $\begin{array}{l}\text { Sal comum } \\
\text { Salt }\end{array}$ & 0,318 & 0,318 & 0,318 & 0,318 & 0,318 \\
\hline $\begin{array}{l}\text { BHT } \\
\text { Óleo de soja }\end{array}$ & $\begin{array}{l}0,010 \\
0,742\end{array}$ & $\begin{array}{l}0,010 \\
0,742\end{array}$ & $\begin{array}{l}0,010 \\
0,742\end{array}$ & $\begin{array}{l}0,010 \\
0,742\end{array}$ & $\begin{array}{l}0,010 \\
0,742\end{array}$ \\
\hline $\begin{array}{l}\text { Soybean oil } \\
\text { Areia lavada } \\
\text { Washed sand }\end{array}$ & 1,390 & 1,106 & 0,821 & 0,545 & 0,262 \\
\hline $\begin{array}{l}\text { Composição calculada } \\
\text { Calculated composition } \\
\end{array}$ & & & & & \\
\hline $\begin{array}{l}\text { Proteína bruta }(\%) \\
\text { Crude protein }\end{array}$ & 16 & 17 & 18 & 19 & 20 \\
\hline $\begin{array}{l}\text { Energia digestível }(\mathrm{kcal} / \mathrm{kg}) \\
\text { Digestible energy }\end{array}$ & 3400 & 3400 & 3400 & 3400 & 3400 \\
\hline $\begin{array}{l}\text { Lisina }(\%) \\
\text { Lysine }\end{array}$ & 0,889 & 0,944 & 1,000 & 1,055 & 1,111 \\
\hline $\begin{array}{l}\text { Lisina digestível }(\%) \\
\text { Digestible lysine }\end{array}$ & 0,785 & 0,834 & 0,880 & 0,932 & 0,981 \\
\hline $\begin{array}{l}\text { Relação lisina:proteína }(\%) \\
\text { Lysine:protein ratio }\end{array}$ & 5,56 & 5,56 & 5,56 & 5,56 & 5,56 \\
\hline $\begin{array}{l}\text { Relação lisina dig.: treonina digestível (\%) } \\
\text { Lysine dig:threonine dig ratio }\end{array}$ & 71,9 & 71,9 & 71,9 & 71,9 & 71,9 \\
\hline $\begin{array}{l}\text { Relação lisina dig.: metionina dig. }(\%) \\
\text { Lysine dig:methionine dig ratio }\end{array}$ & 32,5 & 32,5 & 32,5 & 32,5 & 32,5 \\
\hline $\begin{array}{l}\text { Cálcio }(\%) \\
\text { Calcium }\end{array}$ & 0,600 & 0,600 & 0,600 & 0,600 & 0,600 \\
\hline $\begin{array}{l}\text { Fósforo total }(\%) \\
\text { Total phosphorus }\end{array}$ & 0,450 & 0,450 & 0,450 & 0,450 & 0,450 \\
\hline 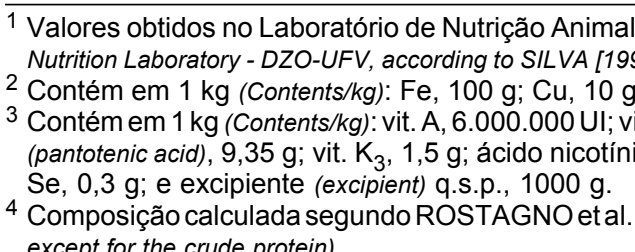 & $\begin{array}{l}\mathrm{ZO} / \mathrm{UFV} \text {, } \\
1 \mathrm{~g} ; \mathrm{Mn}, \\
1.500 .00 \\
\text { cotinic aci } \\
\text { ), com ex }\end{array}$ & $\begin{array}{l}\text { com metc } \\
00 \mathrm{~g} ; \mathrm{I}, 1 \\
15.000 .0 \mathrm{C} \\
\text { it. B12, } 2 \\
\text { roteína br }\end{array}$ & $\begin{array}{l}\text { ipcrita po } \\
\text { ipiente } \\
1,1,35 \mathrm{~g} ; \\
\text { lo fólico } \\
\text { ated compc }\end{array}$ & $\begin{array}{l}\text { 990) (Valc } \\
\text { t) q.s.p., } \\
\text { vit. } \mathrm{B}_{6}, 2 \mathrm{~g} \\
0,6 \mathrm{~g} ; \text { bic } \\
\text { ding to } R O\end{array}$ & $\begin{array}{l}\text { in Animal } \\
\text { totênico } \\
\text {, 0,08 g; } \\
\text { al. (1992), }\end{array}$ \\
\hline
\end{tabular}


ína, de lisina e de energia digestível e conversão alimentar) e tamanho de órgãos foram realizadas utilizando-se o programa computacional SAEG (Sistema para Análises Estatísticas e Genéticas), desenvolvido na UNIVERSIDADE FEDERAL DE VIÇOSA - UFV (1997).

A estimativa da exigência de proteína bruta foi feita com base nos resultados de ganho de peso, conversão alimentar e consumos de ração, proteína e lisina, utilizando-se o modelo de regressão linear, quadrática e, ou "Linear Response Plateau" (LRP) conforme o melhor ajuste.

\section{Resultados e Discussão}

A temperatura interna da sala manteve-se, durante o período experimental, em $21,3 \pm 0,53^{\circ} \mathrm{C}$, com umidade relativa de $70,5 \pm 5,11 \%$, temperatura de globo negro de $21,8 \pm 0,53^{\circ} \mathrm{C}$ e índice de temperatura de globo e umidade (ITGU) calculado em 68,7 $\pm 0,93$. $O$ valor de ITGU, que caracterizou o ambiente termoneutro neste trabalho, foi similar àquele de $69,1 \pm 1,19$ verificado por TAVARES et al. (2000), em trabalho conduzido com suínos de 30 a $60 \mathrm{~kg}$ mantidos em ambiente de conforto térmico.

Os resultados de desempenho, consumo de proteína, lisina e energia digestível diários e das taxas de deposição de proteína na carcaça das leitoas dos 30 aos $60 \mathrm{~kg}$ encontram-se na Tabela 2. O ganho de peso diário (GPD) aumentou de forma linear $(\mathrm{P}<0,10)$, em razão dos níveis crescentes de proteína bruta $(\mathrm{PB})$ das rações. No entanto, o modelo "Linear Response Plateau" (LRP) foi o que melhor se ajustou aos dados, estimando em $18,78 \%$, o nível a partir do qual o GPD permaneceu em um platô (Figura 1).

Melhora no GPD de suínos na fase de crescimento, em razão do aumento do nível de proteína da ração, tem sido observada por diferentes autores (CASTELL et al., 1994; CHIBA, 1994; EDMONDS et al., 1998).

Apesar da similaridade dos resultados dos trabalhos quanto aos efeitos positivos dos níveis de proteína sobre o GPD, os níveis nos quais foram obtidos os melhores resultados diferem significativamente. Este fato, provavelmente, está associado à diferença entre a genética dos animais, quanto ao potencial de crescimento, entre outros fatores.

Estes resultados também estão coerentes com aqueles obtidos por FULLER et al. (1995) e KEMM et al. (1995) que, avaliando níveis de proteína bruta para suínos, mantidos em ambiente termoneutro, não constataram melhora no GPD das leitoas na fase de crescimento, com nível de proteína acima de 18 e $18,5 \%$, respectivamente.

Como entre os tratamentos não ocorreu variação

Tabela 2 - Resultados de desempenho, consumos de proteína, lisina total e energia digestível e relação lisina:energia, de leitoas dos 30 aos $60 \mathrm{~kg}$, recebendo rações com níveis crescentes de proteína bruta

Table 2 - Results of performance, protein, lysine and digestible energy intakes and energy:lysine ratio of gilts from 30 to $60 \mathrm{~kg}$ fed diets with crescent levels of crude protein

\begin{tabular}{|c|c|c|c|c|c|c|}
\hline \multirow[t]{2}{*}{$\begin{array}{l}\text { Variáveis } \\
\text { Variables }\end{array}$} & \multicolumn{5}{|c|}{$\begin{array}{c}\text { Níveis de proteína bruta }(\%) \\
\text { Crude protein levels }\end{array}$} & \multirow[t]{2}{*}{$\mathrm{CV}(\%)$} \\
\hline & 16 & 17 & 18 & 19 & 20 & \\
\hline $\begin{array}{l}\text { Ganho de peso }(\mathrm{g} / \mathrm{dia})^{1} \\
\text { Weight gain }\end{array}$ & 858 & 867 & 897 & 902 & 902 & 4,8 \\
\hline $\begin{array}{l}\text { Consumo de ração (g/dia) } \\
\text { Ration intake }\end{array}$ & 1810 & 1805 & 1816 & 1796 & 1783 & 5,4 \\
\hline $\begin{array}{l}\text { Consumo de proteína }(\mathrm{g} / \mathrm{dia})^{2} \\
\text { Protein intake }\end{array}$ & 290 & 307 & 327 & 341 & 357 & 5,7 \\
\hline $\begin{array}{l}\text { Consumo de lisina total }(\mathrm{g} / \mathrm{dia})^{2} \\
\text { Lysine intake }\end{array}$ & 16,09 & 17,04 & 18,16 & 18,95 & 19,81 & 5,7 \\
\hline $\begin{array}{l}\text { Consumo de } \mathrm{ED}(\mathrm{kcal} / \mathrm{dia}) \\
\text { DE intake }\end{array}$ & 6155 & 6137 & 6174 & 6106 & 6062 & 5,4 \\
\hline $\begin{array}{l}\text { Conversão alimentar }{ }^{2} \\
\text { Feed:gain ratio }\end{array}$ & 2,11 & 2,08 & 2,03 & 1,99 & 1,98 & 4,1 \\
\hline $\begin{array}{l}\text { Relação lisina:energia (g/Mcal) } \\
\text { Lysine energy ratio }\end{array}$ & 2,61 & 2,77 & 2,94 & 3,10 & 3,27 & \\
\hline $\begin{array}{l}\text { Relação lisina:ganho }(\mathrm{g} / \mathrm{g}) \\
\text { Lysine:gain ratio }\end{array}$ & 18,75 & 19,65 & 20,24 & 21,00 & 21,96 & \\
\hline
\end{tabular}

1,2 Efeito linear $(P<0,10)$ e $(P<0,02)$, respectivamente (Linear effect $[P<.01]$ and $[P<.02]$, respectively).

CV - Coeficiente de variação (Coefficient of variation). 
na qualidade da proteína, que teve a lisina como primeiro aminoácido limitante, a melhora do GPD pode ser atribuída ao aumento do consumo de proteína e, consequentemente, de lisina. De acordo com NOBLET et al. (1987) os suínos têm sua faixa de crescimento limitada pelo consumo de consumo de lisina, que se constitui no primeiro aminoácido limitante para ganho de peso destes animais.

Não se observou efeito $(\mathrm{P}>0,10)$ dos níveis de $\mathrm{PB}$ sobre o consumo de ração (CRD), evidenciando que o aumento observado no GPD ocorreu em razão da melhora na eficiência da utilização do alimento. Resultados semelhantes foram obtidos por CASTELL et al. (1994) e EDMONDS et al. (1998), que não observaram diferenças significativas no consumo de ração de suínos, em crescimento, devido ao aumento do nível de PB da ração.

Apesar de não ter ocorrido diferença significativa, verificou-se que nos dois maiores níveis de PB avaliados, o CRD tendeu a reduzir, sendo os únicos que ficarão abaixo de $1800 \mathrm{~g} /$ dia. Este resultado estaria indicando que, principalmente, o nível de $21 \%$ de PB poderia estar acima da demando do animal. Este relato esta coerente com os resultados obtidos por QUINIOU et al. (1995) que trabalhando com suínos em crescimento observaram que os animais que receberam ração com alto nível de PB (24,3\%) diminuíram consumo diário de MS e de energia.

Não obstante a falta de variação no consumo de ração foi observado o aumento linear $(\mathrm{P}<0,02)$ nos

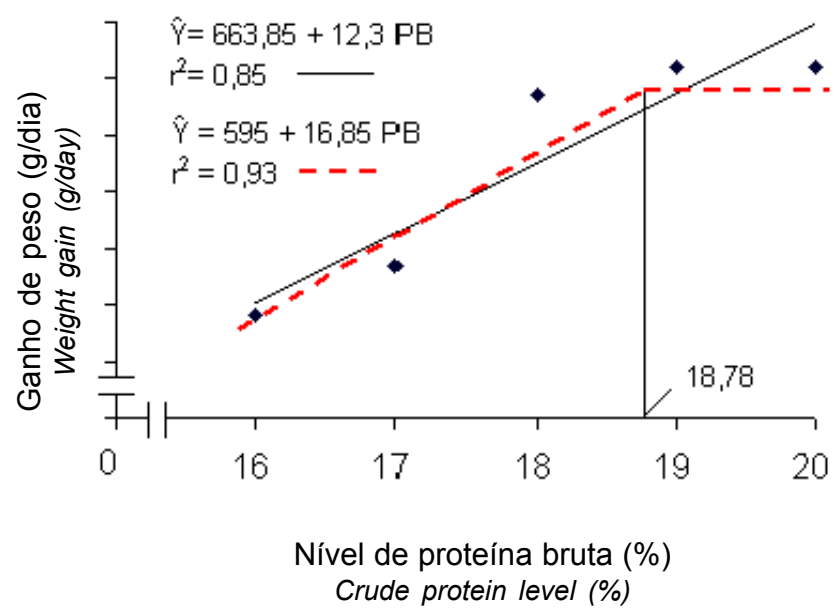

Figura 1 - Efeito do nível de PB da ração sobre o ganho de peso diário de leitoas de 30 a $60 \mathrm{~kg}$, mantidas em ambiente de conforto térmico.

Figure 1 - Effect of CP level on daily weight gain of gilts from 30 to $60 \mathrm{~kg}$ kept under thermal comfort environment. consumos de proteína (CPD) e de lisina (CLD) diários, segundo as equações $=21,275+16,831 \mathrm{~PB}\left(\mathrm{r}^{2}=1,00\right)$ e $=1,19624+0,934061 \mathrm{~PB}\left(\mathrm{r}^{2}=1,00\right)$, respectivamente. Estes aumentos estão diretamente relacionados com as concentrações de proteína e lisina das rações.

No nível de proteína $(18,78 \%)$ que proporcionou o melhor GPD, o consumo estimado de lisina por kg de ganho correspondeu a 18,74 g. Este valor diferiu daquele calculado de dados obtidos por CASTELL et al. (1994) com leitoas em crescimento, que correspondeu a 21,1 g. No entanto, está consistente com o relato de NOBLET et al. (1987) que afirmaram que para suínos dos 20 aos $50 \mathrm{~kg}$, mantidos em ambiente de termoneutralidade, a quantidade de lisina requerida por $\mathrm{kg}$ de ganho de peso é de no mínimo $19,0 \mathrm{~g}$, quando a lisina é o primeiro aminoácido limitante da ração.

Com relação ao consumo de energia digestível diário $(\mathrm{CED})$, não se constatou variação $(\mathrm{P}>0,10)$ devido ao nível de $\mathrm{PB}$ da ração, o que pode ser justificado pelo fato de as rações terem sido isoenergéticas e de não ter ocorrido variação no CRD entre os tratamentos. Diferentes autores (EDMONDS et al., 1998; HANNAS et al., 2000) também não observaram efeito do nível de $\mathrm{PB}$ da ração sobre o CED de suínos na fase de crescimento.

A conversão alimentar $(\mathrm{CA})$ melhorou $(\mathrm{P}<0,02)$ de forma linear, em razão dos níveis de $\mathrm{PB}$ das rações. No entanto, o modelo LRP foi o que melhor se ajustou aos dados, estimando em 19,15\%, o nível a partir do qual a CA, permaneceu em um platô (Figura 2).

Corroborando os resultados obtidos neste traba1ho, CASTELL et al. (1994), CHIBA et al. (1994), QUINIOU et al. (1995) e HANNAS et al. (2000), também observaram efeito positivo dos níveis de proteína sobre a CA de suínos em crescimento, muito embora ocorressem discrepâncias entre os valores de $\mathrm{PB}$ nos quais foram obtidos os melhores resultados de CA. Possíveis fatores como a genética dos animais, o ambiente e a composição das rações experimentais podem justificar esta variação.

A melhora do GPDe CA dos animais, observada neste trabalho, pode ser atribuída ao aumento linear na relação lisina:energia digestível, ocorrido entre os tratamentos.

Diversos autores, entre eles CHIBA et al. (1991), CASTELL et al. (1994) e mais recentemente SMITH et al. (1999), associaram a melhora de desempenho (GPD e CA), de suínos em fase de crescimento, ao aumento da relação lisina:energia das rações.

Os níveis de PB (18,78 e 19,15\%) e os correspondentes consumos de lisina $(18,74$ e 19,08 g) que 
proporcionaram os melhores resultados de desempenho neste trabalho, revelaram que o nível de proteína de $18 \%$, associado ao consumo de lisina de $17,5 \mathrm{~g} / \mathrm{dia}$, preconizados pelo NRC (1998), para suínos de 20 a 50 $\mathrm{kg}$, não atendeu as exigências destes animais. Este fato torna evidente a necessidade de se estabelecer os níveis nutricionais de acordo com a genética do animal (NRC, 1998).

A melhora ocorrida na eficiência do ganho, estaria indicando que pode ter ocorrido variação na composição do ganho. Segundo NOBLET et al. (1994) a composição do ganho dos suínos pode ser alterada em razão da concentração de $\mathrm{PB}$ da ração.

Os valores de peso absoluto, expresso em gramas, e relativo, expresso como porcentagem da carcaça, dos órgãos (coração, estômago, fígado, pulmões, rins e intestinos delgado), estão apresentados na Tabela 3.

Não se observou efeito do nível de PB da ração sobre os pesos, absoluto e relativo, do coração, estômago, rins e intestino delgado. $\mathrm{O}$ peso absoluto do pulmão não foi influenciado pelos tratamentos, enquanto o peso relativo $(\mathrm{P}<0,03)$ aumentou de forma quadrática até o nível de $18,37 \%$ de $\mathrm{PB}$, segundo a equação $\hat{\mathrm{Y}}=2115,02+276,851 \mathrm{~PB}-7,53398$ PB2 $\left(\mathrm{r}^{2}=0,82\right)$.

Os níveis de $\mathrm{PB}$ da ração influenciaram de forma linear crescentes os pesos absoluto $(\mathrm{P}<0,01)$ e relativo $(\mathrm{P}<0,06)$ do fígado, segundo as equações $\hat{\mathrm{Y}}=793,466+27,7365 \mathrm{~PB}\left(\mathrm{r}^{2}=0,84\right)$ e $\hat{\mathrm{Y}}=1,6217+$

Tabela 3 - Pesos absoluto, expresso em gramas, e relativo, expresso como porcentagem da carcaça, do coração, estômago, fígado, pulmões, rins e intestinos delgado de leitoas de $60 \mathrm{~kg}$, alimentadas com rações contendo níveis crescentes de proteína bruta e mantidas em ambiente de conforto térmico

Table 3 - Absolute, expressed in grams, and relative, expressed as percentage of carcass, of heart, stomach, liver, lung, kidneys and of gilts of $60 \mathrm{~kg}$ fed diets with crescent levels of crude protein and kept under termoneutral environment

\begin{tabular}{|c|c|c|c|c|c|c|}
\hline \multirow[t]{2}{*}{$\begin{array}{l}\text { Variáveis } \\
\text { Variables }\end{array}$} & \multicolumn{5}{|c|}{$\begin{array}{c}\text { Níveis de proteína bruta (\%) } \\
\text { Crude protein levels }\end{array}$} & \multirow[t]{2}{*}{$\mathrm{CV}(\%)$} \\
\hline & 16 & 17 & 18 & 19 & 20 & \\
\hline \multicolumn{7}{|l|}{$\begin{array}{l}\text { Peso absoluto (g) } \\
\text { Absolute weight }\end{array}$} \\
\hline $\begin{array}{l}\text { Coração } \\
\text { Heart }\end{array}$ & 235 & 204 & 204 & 218 & 221 & 5,20 \\
\hline $\begin{array}{l}\text { Estômago } \\
\text { Stomach }\end{array}$ & 346 & 344 & 348 & 355 & 368 & 9,33 \\
\hline $\begin{array}{l}\text { Fígado } \\
\text { Liver }\end{array}$ & 1255 & 1257 & 1277 & 1298 & 1370 & 5,03 \\
\hline $\begin{array}{l}\text { Pulmões } \\
\text { Lungs }\end{array}$ & 389 & 403 & 442 & 419 & 410 & 9,50 \\
\hline $\begin{array}{l}\text { Rins } \\
\text { Kidneys }\end{array}$ & 245 & 233 & 253 & 227 & 251 & 12,80 \\
\hline $\begin{array}{l}\text { Intestino delgado } \\
\text { Gut }\end{array}$ & 1116 & 1265 & 1294 & 1196 & 1220 & 10,13 \\
\hline $\begin{array}{l}\text { Comprimento (m) } \\
\text { Lenght }\end{array}$ & & & & & & \\
\hline $\begin{array}{l}\text { Intestino delgado } \\
\text { Gut } \\
\text { Peso relativo (\%) }\end{array}$ & 18,60 & 18,27 & 18,98 & 18,46 & 18,50 & 6,69 \\
\hline $\begin{array}{l}\text { Relative weight } \\
\text { Coração }\end{array}$ & 0,50 & 0,46 & 0,46 & 0,48 & 0,48 & 6,42 \\
\hline $\begin{array}{l}\text { Heart } \\
\text { Estômago } \\
\text { Stomach }\end{array}$ & 0,75 & 0,76 & 0,78 & 0,78 & 0,80 & 9,52 \\
\hline $\begin{array}{l}\text { Fígado }^{1} \\
\text { Liver }\end{array}$ & 2,70 & 2,78 & 2,87 & 2,88 & 2,99 & 7,90 \\
\hline $\begin{array}{l}\text { Pulmões } \\
\text { Lungs }\end{array}$ & 0,84 & 0,88 & 0,99 & 0,92 & 0,89 & 6,51 \\
\hline $\begin{array}{l}\text { Rins } \\
\text { Kidneys }\end{array}$ & 0,53 & 0,52 & 0,57 & 0,50 & 0,55 & 13,46 \\
\hline $\begin{array}{l}\text { Intestino delgado } \\
\text { Gut }\end{array}$ & 2,40 & 2,80 & 2,90 & 2,63 & 2,67 & 12,17 \\
\hline
\end{tabular}

1 Efeito linear $(P<0,01)$ e $(P<0,06)$ (Linear effect $[P<0.01]$ and $[P<0.06])$.

2 Efeito quadrático $(P<0,03)$ (Quadract effect $[P<0.003])$. 


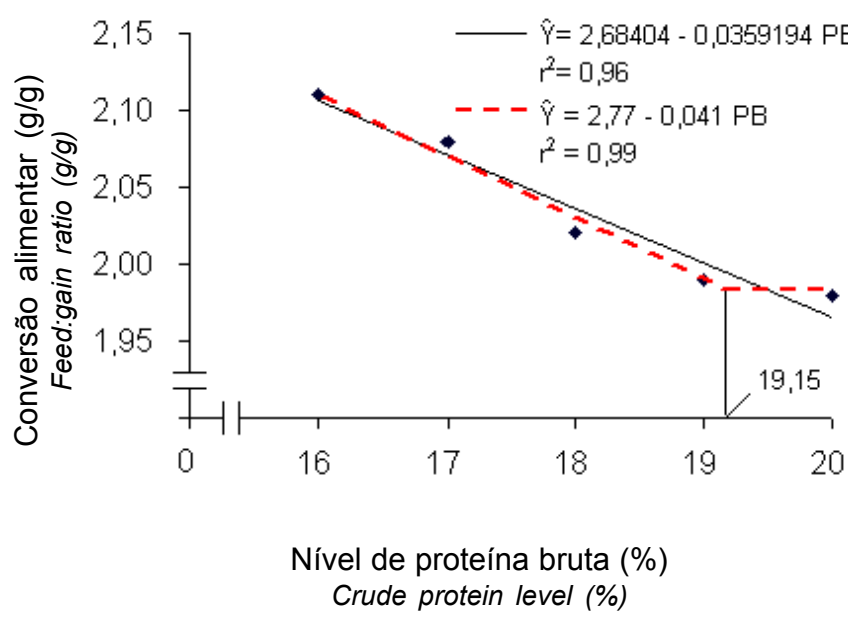

Figura 2 - Efeito do nível de PB da ração sobre a conversão alimentar $(\mathrm{g} / \mathrm{g})$ de leitoas de $30 \mathrm{a} 60 \mathrm{~kg}$, mantidas em ambiente de conforto térmico $\left(21^{\circ} \mathrm{C}\right)$.

Figure 2 - Effect of CP level on feed:gain ratio of gilts from 30 to $60 \mathrm{~kg}$ kept under thermal comfort environment.

$0,0681564 \mathrm{~PB}\left(\mathrm{r}^{2}=0,89\right)$, respectivamente. Estes resultados estão em acordo com aqueles obtidos por HANNAS (1999), que atribuíram o aumento no peso do fígado, ao aumento no consumo de PB.

\section{Conclusões}

Leitoas em crescimento, mantidas em ambiente de conforto térmico, exigem $19,15 \%$ de $\mathrm{PB}$ na ração, correspondendo a um consumo de 343 e 19,08 g/dia de proteína e lisina total, respectivamente, para o melhor desempenho.

\section{Referências Bibliográficas}

BUFFINGTON, D.E., COLAZZO-AROCHO, A., CANTON, G.H. et al. 1981. Black globe-humidity index (BGHI) as comfort equation for dairy cows. Transaction of the ASAE, 24:711-714.

CASTELL, A.G., CLIPLEF, R.L., POSTE-FLYNN, L.M. et al. 1994. Performance, carcass and pork characteristics of castrates and gilts self-fed diets differing in protein content and lysine:energy ratio. Can. J. Anim. Sci., 74:519-528.

CHIBA, L.I. 1994. Effects of dietary amino acid content between 20 and $50 \mathrm{~kg}$ and 50 and $100 \mathrm{~kg}$ live weight on the subsequent and overall performance of pigs. Livest. Prod. Sci., 39:213-221.

EDMONDS, M.S., ARENTSON, B.E., MENTE, G.A. 1998. Effect of protein levels and space allocations on performance of growing-finishing pigs. J. Anim. Sci., 76:814-821.

FERREIRA, R.A., FIALHO, E.T., LIMA, J.A.F. Criação técnica de suínos - Boletim Técnico da UFLA, ano V, n.3, 1996.

FULLER, M.F., FRANKILIN, M.F., McWILLIAM, R. et al. 1995. The responses of growing pigs, of different sex and genotype, to dietary energy and protein. Anim. Sci., 60:291-298. HANNAS, M.I., OLIVEIRA, R.F.M., DONZELE, J.L. et al. 2000. Proteína bruta para suínos machos castrados mantidos em ambiente de conforto térmico dos 15 aos $30 \mathrm{~kg}$. Rev. bras. zootec., 29(2):476-484.

KEMM, E.H., SIEBRITS, F.K., RAS, M.N. et al. 1995. Feed intake, growth and protein deposition of pigs fed three protein levels. Livest. Prod. Sci., 41:163-170.

LOPEZ, J., GOODBAND, R.D., ALLEE, G.W. et al. 1994. The effects of diets formulated on ideal protein basis on growth performance, carcass characteristics, and thermal balance of finishing gilts housed in a hot, diurnal environment. J. Anim. Sci., 72:367-379.

MÖHN, S., LANGE, C.F.M. 1998. The effect of body weight on the upper limit to protein deposition in a defined population of growing gilts. J. Anim. Sci., 76:124-133.

NOBLET, J., HENRY, Y., DUBOIS, S. 1987. Effect of protein and lysine levels in the diet on body gain composition and energy utilization in growing pigs. J. Anim. Sci., 65:717-726.

NATIONAL RESEARCH COUNCIL - NRC. 1998. Committee on Animal Nutrition. Subcommittee of Swine Nutrition. Washington. Nutrient requirements of swine. 10.ed., Washington: National Academic of Sciences. 189p.

OLIVEIRA, R.F.M. Efeito do nível de energia digestivel e da temperatura ambiente sobre o desempenho e sobre parâmetros fisiológicos e hormonal de suínos dos 15 aos $30 \mathrm{~kg}$. Viçosa, MG: UFV, 1996. 139p. Tese (Doutorado em Zootecnia) Universidade Federal de Viçosa, 1996.

QUINIOU, N., DUBOIS, S., NOBLET, J. 1995. Effect of dietary crude protein level on protein and energy balances in growing pigs: comparison of two measurement methods. Livest. Prod. Sci., 41:51-61.

RHODIMET nutrition guide. 1993. Rhodimet nutrition guide. Rhône-Poulenc Animal Nutrition, 2.ed. France. 55p.

REEDS, P.J., WAHLE, K.W., HAGGARTY, P. 1982. Energy cost of protein and fatty acid synthesis. Proc. Nutr. Soc., 41:155-159.

ROSTAGNO, H.S., SILVA, D.J., COSTA, P.M.A. et al. 1992. Composição de alimentos e exigências nutricionais de aves e suínos: tabelas brasileiras. Viçosa, MG: UFV. 59p.

SILVA, D.J. 1990. Análise de alimentos: métodos químicos e biológicos. 2.ed. Viçosa, MG: UFV. 166p.

SMITH, J.W., TOKACH, M.D., O'QUINN, P.R. et al. 1999. Effects of dietary energy density and lysine:calorie ratio on growth performance and carcass characteristics of growingfinishing pigs. J. Anim. Sci., 77:3007-3015.

TAVARES, S.L.S., DONZELE, J.L., OLIVEIRA, R.F.M. et al. 2000. Influência da temperatura ambiente sobre o desempenho e os parâmetros fisiológicos de suínos machos castrados dos 30 aos 60 kg. Rev. bras. zootec., 29(1):199-205.

UNIVERSIDADE FEDERAL DE VIÇOSA - UFV. 1997. SAEG - Sistemas de análises estáticas e genéticas. Versão 7.1. Viçosa, MG. 150p. (Manual do usuário). 